\title{
microRNA based prognostic biomarkers in pancreatic Cancer
}

\author{
Shixiang Guo ${ }^{1,2}$, Andrew Fesler ${ }^{1}$, Huaizhi Wang ${ }^{2}$ and Jingfang Ju ${ }^{{ }^{*}}$
}

\begin{abstract}
Despite tremendous research efforts focused on diagnosis and treatment, pancreatic ductal adenocarcinoma remains the third leading cause of cancer-related death in the United States, with a 5-year overall survival rate of less than $5 \%$. Although resistance is rather complex, emerging evidence has demonstrated that epigenetic alterations (e.g. miRNA) have important roles in PDAC progression as well as resistance to therapy. Certain miRNAs have been identified as potential prognostic biomarkers in PDAC. In this review, we summarize the recent developments in miRNA research related to PDAC therapeutic resistance mechanisms and the potential of miRNAs as prognostic biomarkers for future clinical management of PDAC.
\end{abstract}

Keywords: Pancreatic ductal adenocarcinoma, miRNA, Biomarkers, Resistance, Prognosis, Chemotherapy, Gemcitabine

\section{Background}

Pancreatic ductal adenocarcinoma (PDAC) is the third deadliest cancer in the United States [1]. It is characterized by late clinical presentation, early metastasis and poor prognosis [2]. A large proportion of patients are diagnosed with locally advanced or metastatic disease at the time of presentation [3]. Current therapy for PDAC mainly involves surgical resection, adjuvant chemotherapy and radiotherapy [4]. Despite the advancement in clinical management (e.g. Abraxane), patient outcomes remain unsatisfactory $[5,6]$.

In addition to patients presenting with advanced disease, many patients also experience early appearance of post-operative recurrence [7]. Therefore, adjuvant treatments (chemotherapy, radiotherapy etc.) are necessary and critical for management of patients with advanced disease. However, few effective chemotherapeutic options exist for advanced PDAC patients in the clinic. Since 1997, gemcitabine has been approved as the standard first-line chemotherapeutic, several novel therapeutic regimens based on gemcitabine have also been investigated for PDAC treatment [8]. Multiple agents have been assessed in combination with gemcitabine including 5-fluorouracil, oxaliplatin, cisplatin and capecitabine

\footnotetext{
* Correspondence: jingfang.ju@stonybrookmedicine.edu

${ }^{1}$ Stony Brook University, Stony Brook, New York 11794, USA Full list of author information is available at the end of the article
}

[9-12]. However, the impact on patient survival is rather limited. Such failure is caused, at least in part, by chemoresistance. Chemoresistance is mainly classified into intrinsic and acquired resistance. Compared with intrinsic resistance where therapy is ineffective from the start of treatment, acquired resistance with continuous chemotherapy ultimately causes relapse and metastasis [13]. Over the past decade extensive research efforts have been dedicated to investigate the underlying mechanisms of chemoresistance. Resistance involves PDAC stem cells which have unique characteristics including enhanced epithelial-mesenchymal transition (EMT), autophagy, and altered metabolism that contributes to their plastic nature and chemoresistant phenotype. Altered expression of many different genes (e.g. KRAS, TP53, CCND1, BCL-2, BIRC5) and changes in key signaling pathways (e.g. Notch, PI3K/AKT, NF- $k B$, Hedgehog, cell cycle, apoptosis) also contribute to resistance [13-16]. Clearly there is an urgent need to develop early detection and/or novel prognostic biomarkers to help better manage PDAC treatment to maximize survival benefits and to avoid toxicity.

\section{Epigenetic regulations mediated by miRNAs in PDAC resistance mechanism}

Based on a large body of growing evidence, we know PDAC resistance is regulated, at least in part, by epigenetic alterations including miRNA. miRNAs are small non-coding RNAs 18-22 nucleotides in length that have 
been identified to be associated with tumorigenesis, cell cycle control, apoptosis, proliferation, chemoresistance, invasion and metastasis [17]. In PDAC, miRNAs have been demonstrated to modulate key targets and pathways such as KRAS, TP53, PI3K/AKT, NF-kB and Hedgehog signaling, and their aberrant expression is associated with chemoresistance (14). It has been shown that miR-17-92 cluster counteracts quiescence and chemoresistance in a distinct subpopulation of pancreatic cancer stem cells by acting through the NODAL/ACTIVIN/TGF- $\beta 1$ signaling cascade [18]. A number of important miRNAs in PDAC are listed in Table 1.

In terms of resistance of PDAC to chemotherapeutic treatment, miR-21 is one of the most investigated oncogenic miRNAs related to gemcitabine resistance. Elevated expression of miR-21 inhibits the anti-tumor activity of gemcitabine, and is significantly associated with shorter survival time [19]. Giovannetti et al. suggests that miR-21 contributes to gemcitabine chemoresistance by inhibiting tumor suppressor gene phosphatase and tensin homologue (PTEN), thereby activating the PI3K/AKT pathway [20]. Park et al. illustrated that silencing miR-21 leads to cell cycle arrest (G1 phase) and induction of apoptosis by up-regulating PTEN [21]. Hwang et al. showed that down-regulation of miR-21 expression correlates with prolong overall survival and benefit from chemotherapeutic treatment [22]. In addition to miR-21, several other miRNAs (miR-34, miR-217, miR-96, miR145) have been shown to be deregulated and impact the
PI3K/AKT pathway in PDAC [14]. EMT/ mesenchymalepithelial transition (MET) has been shown to be critical in chemoresistance of PDAC and is mediated by key miRNAs. Emerging evidence confirms that the miR-200 family plays a key role in chemoresistance via reversing EMT. Ali et al. reported that down-regulation of miR-21 and restoration of miR-200b and miR-200c inactivates pAKT by reactivation of PTEN and reverses EMT, resulted in enhanced gemcitabine sensitivity [19]. Furthermore, Li et al. show that miR-200b, miR-200c, let-7 family (let-7b, let-7c, let-7d, let-7e) are down-regulated in gemcitabine-resistant PDAC cells. Restoration of miR-200 and let-7 results in a reversal of PDAC from EMT to MET and sensitivity to gemcitabine treatment [23].

Previous studies have demonstrated that the miR-34 family (miR-34a, b and c) is associated with p53 and p38-MAPK pathways in response to DNA damage [24]. Down-regulation of miR-34 is responsible for progression of various malignancies including PDAC, lung, breast, prostate and liver cancer [25]. miR-34 has an anti-cancer role via modulating targets implicated in apoptosis, cell cycle, and DNA repair, such as $\mathrm{NOTCH}$, BCL2, VEGFA, CCND1 and CDK6 [26]. In regards to PDAC resistance, Ji et al. reported that miR-34 is regulated by $\mathrm{p} 53$, and inhibits target genes $\mathrm{NOTCH}$ and BCL-2. Loss of miR-34 leads to the enrichment of cancer stem cells or tumor-initiating cells and restoration of miR-34 inhibits PDAC cell growth and enhanced chemotherapeutic sensitivity to gemcitabine [27].

Table 1 Critical miRNAs as potential diagnostic, therapeutic, prognostic targets in PDAC

\begin{tabular}{|c|c|c|c|c|c|}
\hline miRNAs & Function & $\begin{array}{l}\text { Expression in } \\
\text { tumor }\end{array}$ & Targets & Pathway & Ref. \\
\hline miR-21 & Oncogenic & Up-regulated & $\begin{array}{l}\text { PTEN, PDCD4, CDK6, CDKN1A, IL-6R, FAS, TPM1, APAF1, } \\
\text { SOCS5 }\end{array}$ & PI3K/AKT & [20-22] \\
\hline miR-34 & $\begin{array}{l}\text { Tumor } \\
\text { suppressor }\end{array}$ & Down-regulated & NOTCH, BCL2, VEGFA, CCND1, CDK6 & $\begin{array}{l}\text { p53/p38-MAPK/NOTCH PI3K } \\
\text { AKT }\end{array}$ & $\begin{array}{l}{[14,24,} \\
26]\end{array}$ \\
\hline $\begin{array}{l}\text { miR-200 } \\
\text { family }\end{array}$ & $\begin{array}{l}\text { Tumor } \\
\text { suppressor }\end{array}$ & Down-regulated & E-cadherin, ZEB, Vimentin & NOTCH, EMT & $\begin{array}{l}{[14,20,} \\
23]\end{array}$ \\
\hline Let-7 family & $\begin{array}{l}\text { Tumor } \\
\text { suppressor }\end{array}$ & Down-regulated & KRAS, HRAS, LIN28, HMGA2, NF2, TRIM71 & EMT, KRAS & [16] \\
\hline miR-15a & $\begin{array}{l}\text { Tumor } \\
\text { suppressor }\end{array}$ & Down-regulated & WANT3A, FGF7, BMI-1 & ERK/AKT, EMT & {$[28,29]$} \\
\hline miR-506 & $\begin{array}{l}\text { Tumor } \\
\text { suppressor }\end{array}$ & Down-regulated & SPHK1, PI3M & SPHK1/AKT/NF-KB & {$[31,32]$} \\
\hline miR-221 & Oncogenic & Up-regulated & KIT, CDKN1C, CDKN1B & $\begin{array}{l}\text { EMT, PKC/NF-KB, PTEN/PI3K } \\
\text { AKT }\end{array}$ & {$[14,21]$} \\
\hline miR-96 & $\begin{array}{l}\text { Tumor } \\
\text { suppressor }\end{array}$ & Down-regulated & KRAS, AKT & KRAS, PI3K/AKT & {$[14,15]$} \\
\hline miR-17-92 & $\begin{array}{l}\text { Tumor } \\
\text { suppressor }\end{array}$ & Down-regulated & $\mathrm{p} 21, \mathrm{p} 57, \mathrm{TBX} 3$ & NODAL/ACTIVIN/TGF-1 & [18] \\
\hline miR-145 & $\begin{array}{l}\text { Tumor } \\
\text { suppressor }\end{array}$ & Down-regulated & KRAS, RREB1 & KRAS, PI3K/AKT & [14] \\
\hline miR-155 & Oncogenic & Up-Regulated & TP53INP & $\begin{array}{l}\text { Apoptosis, Exosome } \\
\text { Synthesis }\end{array}$ & [30] \\
\hline
\end{tabular}


Zhang et al. suggested that miR-214 enhances chemoresistance to gemcitabine by down-regulating the tumor suppressor gene ING4, while miR-15a can suppress the growth of chemoresistant PDAC cells via targeting WNT3A and FGF7, contributing to progression and proliferation through the phosphorylation of the kinases ERK and AKT [28]. Moreover, Guo et al. indicated that miR-15a inhibits cell proliferation and EMT by down-regulating BMI-1 in PDAC [29].

miR-155 expression has been shown to induce gemcitabine resistance. Prolonged exposure to gemcitabine leads to increased miR-155 expression, which inhibits apoptosis and increases exosome production, resulting in gemcitabine resistance [30]. Li et al. reported that miR-506 can inhibit cell proliferation, induce cell cycle arrest, promote apoptosis and enhance chemosensitivity to gemcitabine in PDAC by regulating the SPHK1/AKT/ NF- $\mathrm{B}$ s signaling pathway [31]. Meanwhile, Du et al. revealed that miR-506 represses PDAC cell proliferation by targeting PIM3, a member of oncogenic PIM family [32]. Based on these studies, it appears that miR-506 plays a tumor suppressor role in PDAC. The functions of several miRNAs in PDAC are shown in Fig. 1.

\section{miRNAs as prognostic biomarkers}

Based on the poor prognosis of PDAC, the development of early detection methods, more effective treatment options and better prognostic biomarkers are of critical significance. Besides the significance of miRNAs for early detection and diagnosis, accumulating evidence suggests that miRNAs have great potential as prognostic biomarkers [33, 34]. Dillhoff et al. showed that $79 \%$ of PDAC patients with miR-21 high expression have poor outcomes [35]. Bloomston et al. found that six miRNAs (miR-30a-3p, miR-105, miR-127, miR-187, miR-452, and miR-518a-2) are predictive of better prognosis (survival time beyond 2 years) in PDAC patients [36]. One recent study found that over-expression of miR-212 and miR675 and down-regulation of miR-148a, miR-187, and let$7 \mathrm{~g}$ were independent predictors of worse prognosis in PDAC patients [37]. miR-142-5p and miR-204 are found to be down-regulated in chemoresistant PDAC cells, and high expression of these miRNAS in PDAC patients associates with better overall survival [38]. One study has concluded that miR-155, miR-203, miR-210, miR-222, miR-200c and miR-302 are associated with PDAC patients' outcome [39]. In our previous studies, we found that low expression of miR-506 was an independent predictor of poor prognosis in PDAC, while miR-15a is significantly related with prognosis of PDAC patients $[29,31]$. Collectively, these studies support the potential role of miRNAs as prognostic biomarkers for PDAC.

\section{Other class of noncoding RNAs in PDAC resistance and prognosis}

Beyond miRNA, other types of noncoding RNAs (e.g. lncRNA, circRNA) have also been implicated in cancer resistance and prognosis [40-42]. It has been reported that elevated HOTAIR expression is significantly associated with poor prognosis of PDAC patients. HOTAIR

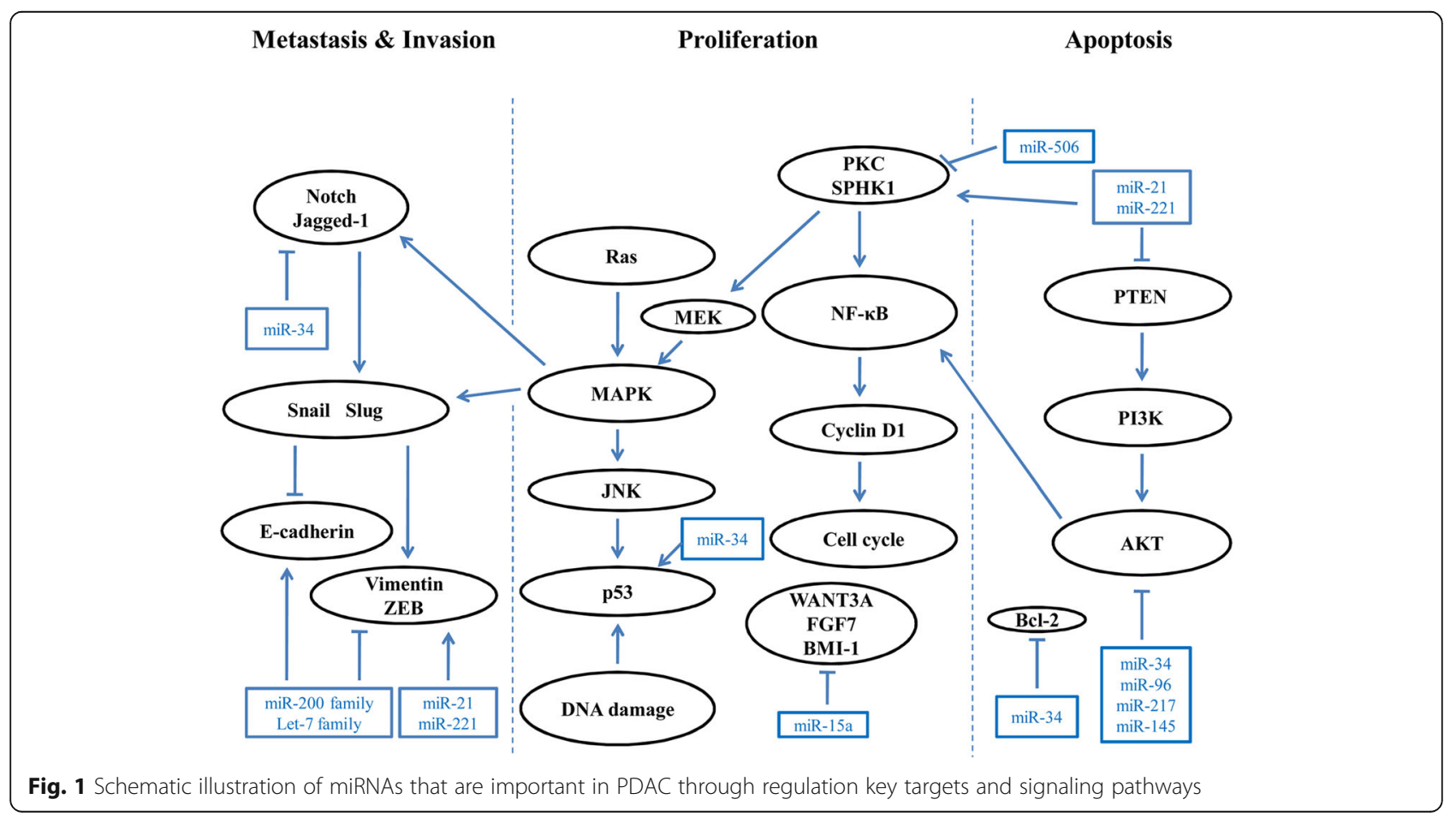


has oncogenic activity by suppressing a number of interferon-related genes and genes related to cell cycle control [43]. Huang et al. recently reported that circular RNA, hsa_circ_0000977, is upregulated in PDAC. Inhibition of hsa_circ_0000977 suppresses PDAC cell proliferation and induces cell cycle arrest. Hsa_circ_0000977 interferes with hsa-miR-874-3p and increases Polo like kinase 1 (PLK1) expression [44]. It is conceivable that we are still at the early stage of exploring other types of noncoding RNAs in PDAC and there will be more exciting discoveries in the future.

\section{Conclusions}

It is clear that PDAC utilizes a variety of mechanisms to maintain a highly resistant phenotype. The highly plastic nature of PDAC resistance is mediated by genetic and epigenetic alterations. The epigenetic controls such as miRNAs allow cells to quickly adapt to the genotoxic stress environment caused by chemotherapy. miRNAs can quickly modulate mRNA translation in PDAC cells in response to chemotherapeutic treatment. As a result, a number of miRNAs have shown great potential as prognostic biomarkers in PDAC. Hopefully these biomarker miRNAs will form a solid foundation to better manage clinical treatment strategies to enhance survival benefits and avoid toxicity. Beyond miRNAs as prognostic biomarkers, as miRNAs are multi-targeted entities that suppress a number of key targets and pathways, some of these miRNAs will be good candidates to develop as novel therapeutics for overcoming PDAC resistance.

\section{Abbreviations \\ circRNA: circular RNA; EMT: Epithelial-mesenchymal transition; IncRNA: long noncoding RNA; MET: Mesenchymal-epithelial transition; PDAC: Pancreatic} ductal adenocarcinoma

\section{Acknowledgements}

The authors apologize to those whose work has not been included in this review due to scope and space limitations.

\section{Funding}

This study was supported by the National Institute of Health/National Cancer Institute R01CA15501904 (J Ju), R01CA19709801 (J Ju) and the National Natural Science Foundation of China No. 81502550 (SX Guo).

\section{Authors' contributions}

SX: Gathered references and drafted the manuscript and made the figure. AF edited the manuscript and figure, and gathered references. HW edited the manuscript and provided additional references. JJ drafted the manuscript, designed the figure and provided funding. All authors read and approved the final manuscript.

\section{Ethics approval and consent to participate}

Not applicable.

\section{Competing interests}

The authors declare that they have no competing interests.

\section{Publisher's Note}

Springer Nature remains neutral with regard to jurisdictional claims in published maps and institutional affiliations.

\section{Author details}

${ }^{1}$ Stony Brook University, Stony Brook, New York 11794, USA. ${ }^{2}$ Third Military Medical University, Chongqing 400038, People's Republic of China.

Received: 16 March 2018 Accepted: 7 May 2018

Published online: 21 May 2018

\section{References}

1. Siegel RL, Miller KD, Jemal A. Cancer statistics, 2018. CA Cancer J Clin. 2018;68:7-30

2. Li D, Xie K, Wolff R, Abbruzzese JL. Pancreatic cancer. Lancet. 2004;363:1049-57.

3. Siegel RL, Miller KD, Jemal A. Cancer statistics, 2017. CA Cancer J Clin. 2017;67:7-30.

4. Wagner M, Redaelli C, Lietz M, Seiler CA, Friess H, Buchler MW. Curative resection is the single most important factor determining outcome in patients with pancreatic adenocarcinoma. Br J Surg. 2004;91:586-94.

5. Hartwig W, Werner J, Jager D, Debus J, Buchler MW. Improvement of surgical results for pancreatic cancer. Lancet Oncol. 2013;14:e476-85.

6. Garrido-Laguna I, Hidalgo M. Pancreatic cancer: from state-of-the-art treatments to promising novel therapies. Nat Rev Clin Oncol. 2015;12:319-34.

7. Matsuno S, Egawa S, Fukuyama S, Motoi F, Sunamura M, Isaji S, Imaizumi T, Okada S, Kato H, Suda K, et al. Pancreatic Cancer registry in Japan: 20 years of experience. Pancreas. 2004;28:219-30.

8. Burris HA 3rd, Moore MJ, Andersen J, Green MR, Rothenberg ML, Modiano MR, Cripps MC, Portenoy RK, Storniolo AM, Tarassoff P, et al. Improvements in survival and clinical benefit with gemcitabine as first-line therapy for patients with advanced pancreas cancer: a randomized trial. J Clin Oncol. 1997;15:2403-13.

9. Berlin JD, Catalano P, Thomas JP, Kugler JW, Haller DG, Benson AB 3rd. Phase III study of gemcitabine in combination with fluorouracil versus gemcitabine alone in patients with advanced pancreatic carcinoma: eastern cooperative oncology group trial E2297. J Clin Oncol. 2002;20:3270-5.

10. Heinemann V, Quietzsch D, Gieseler F, Gonnermann M, Schonekas H, Rost A, Neuhaus H, Haag C, Clemens M, Heinrich B, et al. Randomized phase III trial of gemcitabine plus cisplatin compared with gemcitabine alone in advanced pancreatic cancer. J Clin Oncol. 2006;24:3946-52.

11. Louvet C, Labianca R, Hammel P, Lledo G, Zampino MG, Andre T, Zaniboni A, Ducreux M, Aitini E, Taieb J, et al. Gemcitabine in combination with oxaliplatin compared with gemcitabine alone in locally advanced or metastatic pancreatic cancer: results of a GERCOR and GISCAD phase III trial. J Clin Oncol. 2005;23:3509-16.

12. Herrmann R, Bodoky G, Ruhstaller T, Glimelius B, Bajetta E, Schuller J, Saletti P, Bauer J, Figer A, Pestalozzi B, et al. Gemcitabine plus capecitabine compared with gemcitabine alone in advanced pancreatic cancer: a randomized, multicenter, phase III trial of the Swiss Group for Clinical Cancer Research and the central European cooperative oncology group. J Clin Oncol. 2007;25:2212-7.

13. Wang Z, Li Y, Ahmad A, Banerjee S, Azmi AS, Kong D, Sarkar FH. Pancreatic cancer: understanding and overcoming chemoresistance. Nat Rev Gastroenterol Hepatol. 2011;8:27-33.

14. Drakaki A, lliopoulos D. MicroRNA-gene signaling pathways in pancreatic cancer. Biom J. 2013:36:200-8.

15. Yu S, Lu Z, Liu C, Meng Y, Ma Y, Zhao W, Liu J, Yu J, Chen J. miRNA-96 suppresses KRAS and functions as a tumor suppressor gene in pancreatic cancer. Cancer Res. 2010;70:6015-25.

16. Pai $P$, Rachagani $S$, Are C, Batra SK. Prospects of miRNA-based therapy for pancreatic cancer. Curr Drug Targets. 2013;14:1101-9.

17. Bartel DP. MicroRNAs: genomics, biogenesis, mechanism, and function. Cell. 2004;116:281-97.

18. Cioffi M, Trabulo SM, Sanchez-Ripoll Y, Miranda-Lorenzo I, Lonardo E, Dorado J, Reis Vieira C, Ramirez JC, Hidalgo M, Aicher A, et al. The miR-1792 cluster counteracts quiescence and chemoresistance in a distinct subpopulation of pancreatic cancer stem cells. Gut. 2015;64:1936-48.

19. Ali S, Ahmad A, Banerjee S, Padhye S, Dominiak K, Schaffert JM, Wang Z, Philip PA, Sarkar FH. Gemcitabine sensitivity can be induced in pancreatic cancer cells through modulation of miR-200 and miR-21 expression by curcumin or its analogue CDF. Cancer Res. 2010;70:3606-17.

20. Giovannetti E, Funel N, Peters GJ, Del Chiaro M, Erozenci LA, Vasile E, Leon LG, Pollina LE, Groen A, Falcone A, et al. MicroRNA-21 in pancreatic cancer: correlation with clinical outcome and pharmacologic aspects underlying its role in the modulation of gemcitabine activity. Cancer Res. 2010;70:4528-38. 
21. Park JK, Lee EJ, Esau C, Schmittgen TD. Antisense inhibition of microRNA-21 or -221 arrests cell cycle, induces apoptosis, and sensitizes the effects of gemcitabine in pancreatic adenocarcinoma. Pancreas. 2009;38:e190-9.

22. Hwang JH, Voortman J, Giovannetti E, Steinberg SM, Leon LG, Kim YT, Funel N, Park JK, Kim MA, Kang GH, et al. Identification of microRNA-21 as a biomarker for chemoresistance and clinical outcome following adjuvant therapy in resectable pancreatic cancer. PLoS One. 2010;5:e10630.

23. Li Y, VandenBoom TG 2nd, Kong D, Wang Z, Ali S, Philip PA, Sarkar FH. Upregulation of miR-200 and let-7 by natural agents leads to the reversal of epithelial-to-mesenchymal transition in gemcitabine-resistant pancreatic cancer cells. Cancer Res. 2009;69:6704-12.

24. Kong YW, Ferland-McCollough D, Jackson TJ, Bushell M. microRNAs in cancer management. Lancet Oncol. 2012;13:e249-58.

25. Petrocca F, Lieberman J. Micromanipulating cancer: microRNA-based therapeutics? RNA Biol. 2009:6:335-40.

26. Rokhlin OW, Scheinker VS, Taghiyev AF, Bumcrot D, Glover RA, Cohen MB. MicroRNA-34 mediates AR-dependent p53-induced apoptosis in prostate cancer. Cancer Biol Ther. 2008;7:1288-96.

27. Ji Q, Hao X, Zhang M, Tang W, Yang M, Li L, Xiang D, Desano JT, Bommer GT, Fan D, et al. MicroRNA miR-34 inhibits human pancreatic cancer tumorinitiating cells. PLoS One. 2009:4:e6816.

28. Zhang XJ, Ye H, Zeng CW, He B, Zhang H, Chen YQ. Dysregulation of miR15a and miR-214 in human pancreatic cancer. J Hematol Oncol. 2010:3:46.

29. Guo S, Xu X, Tang Y, Zhang C, Li J, Ouyang Y, Ju J, Bie P, Wang H. miR-15a inhibits cell proliferation and epithelial to mesenchymal transition in pancreatic ductal adenocarcinoma by down-regulating Bmi-1 expression. Cancer Lett. 2014:344:40-6.

30. Mikamori M, Yamada D, Eguchi H, Hasegawa S, Kishimoto T, Tomimaru Y, Asaoka T, Noda T, Wada H, Kawamoto K, et al. MicroRNA-155 controls exosome synthesis and promotes gemcitabine resistance in pancreatic ductal adenocarcinoma. Sci Rep. 2017;7:42339.

31. Li J, Wu H, Li W, Yin L, Guo S, Xu X, Ouyang Y, Zhao Z, Liu S, Tian Y, et al. Downregulated miR-506 expression facilitates pancreatic cancer progression and chemoresistance via SPHK1/Akt/NF-kappaB signaling. Oncogene. 2016;35:5501-14.

32. Du J, Zheng $X$, Cai S, Zhu Z, Tan J, Hu B, Huang Z, Jiao H. MicroRNA506 participates in pancreatic cancer pathogenesis by targeting PIM3. Mol Med Rep. 2015;12:5121-6.

33. Huang J, Liu J, Chen-Xiao K, Zhang X, Lee WN, Go VL, Xiao GG. Advance in microRNA as a potential biomarker for early detection of pancreatic cancer. Biomark Res. 2016;4:20.

34. Liang L, Wei DM, Li JJ, Luo DZ, Chen G, Dang YW, Cai XY. Prognostic microRNAs and their potential molecular mechanism in pancreatic cancer: a study based on the Cancer genome atlas and bioinformatics investigation. Mol Med Rep. 2018;17:939-51.

35. Dillhoff M, Liu J, Frankel W, Croce C, Bloomston M. MicroRNA-21 is overexpressed in pancreatic cancer and a potential predictor of survival. J Gastrointest Surg. 2008;12:2171-6.

36. Bloomston M, Frankel WL, Petrocca F, Volinia S, Alder H, Hagan JP, Liu CG, Bhatt D, Taccioli C, Croce CM. MicroRNA expression patterns to differentiate pancreatic adenocarcinoma from normal pancreas and chronic pancreatitis. JAMA. 2007;297:1901-8.

37. Schultz NA, Andersen KK, Roslind A, Willenbrock H, Wojdemann M, Johansen JS. Prognostic microRNAs in cancer tissue from patients operated for pancreatic cancer-five microRNAs in a prognostic index. World J Surg. 2012;36:2699-707

38. Ohuchida K, Mizumoto K, Kayashima T, Fujita H, Moriyama T, Ohtsuka T, Ueda J, Nagai E, Hashizume M, Tanaka M. MicroRNA expression as a predictive marker for gemcitabine response after surgical resection of pancreatic cancer. Ann Surg Oncol. 2011;18:2381-7.

39. Greither T, Grochola LF, Udelnow A, Lautenschlager C, Wurl P, Taubert H. Elevated expression of microRNAs 155, 203, 210 and 222 in pancreatic tumors is associated with poorer survival. Int J Cancer. 2010;126:73-80

40. Huang X, Xiao R, Pan S, Yang X, Yuan W, Tu Z, Xu M, Zhu Y, Yin Q, Wu Y, et al. Uncovering the roles of long non-coding RNAs in cancer stem cells. J Hematol Oncol. 2017;10:62

41. Dong Y, He D, Peng Z, Peng W, Shi W, Wang J, Li B, Zhang C, Duan C. Circular RNAs in cancer: an emerging key player. J Hematol Oncol. 2017;10:2.

42. Ma P, Pan Y, Li W, Sun C, Liu J, Xu T, Shu Y. Extracellular vesicles-mediated noncoding RNAs transfer in cancer. J Hematol Oncol. 2017;10:57.
43. Kim K, Jutooru I, Chadalapaka G, Johnson G, Frank J, Burghardt R, Kim S, Safe $\mathrm{S}$. HOTAIR is a negative prognostic factor and exhibits pro-oncogenic activity in pancreatic cancer. Oncogene. 2013;32:1616-25.

44. Huang WJ, Wang Y, Liu S, Yang J, Guo SX, Wang L, Wang H, Fan YF. Silencing circular RNA hsa_circ_0000977 suppresses pancreatic ductal adenocarcinoma progression by stimulating miR-874-3p and inhibiting PLK1 expression. Cancer Lett. 2018;422:70-80.

\section{Ready to submit your research? Choose BMC and benefit from:}

- fast, convenient online submission

- thorough peer review by experienced researchers in your field

- rapid publication on acceptance

- support for research data, including large and complex data types

- gold Open Access which fosters wider collaboration and increased citations

- maximum visibility for your research: over $100 \mathrm{M}$ website views per year

At BMC, research is always in progress.

Learn more biomedcentral.com/submissions 